\title{
Potencial do planejamento estratégico de longo prazo para o desenvolvimento das cidades brasileiras
}

\author{
MIGUEL LUIZ BUCALEM I
}

\section{Introdução}

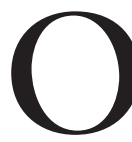

PLANEJAMENTO estratégico para as cidades voltou a ter protagonismo na Europa no final do século passado, depois de ter experimentado certa decadência nos anos 1980 (Albrechts, 2004).

Pesquisa recente no âmbito do projeto do "City Leadership Initiative", uma parceria do "City Leadership Lab" da UCL - University College London, do Banco Mundial e da UN-Habitat, considerou o papel do planejamento estratégico em 143 cidades em nível mundial e, em 29 delas, examinou mais profundamente os respectivos planos estratégicos (Rapoport; Acuto; Grcheva, 2018). Os dados obtidos mostram claramente a importância do planejamento estratégico para esse conjunto de cidades.

A “Cities Alliance” publicou em 2006 (Cities Alliance, 2006) um guia sobre estratégias de desenvolvimento de cidades. Nesse guia, discutem-se os elementos fundamentais de um plano estratégico para as cidades e apresentam-se estudos de casos, ressaltando que grandes transformações podem ocorrer em cidades num período de 10 a 20 anos. O texto destaca, ainda, o potencial dos planos estratégicos como um importante meio para atrair investimentos e priorizar o uso dos recursos.

As Nações Unidas publicaram um relatório global sobre o planejamento de cidades sustentáveis (UN Habitat, 2009) no qual se discute, entre muitos outros temas, o potencial que o planejamento estratégico de longo prazo para as cidades tem para superar dificuldades apresentadas pelo planejamento mais tradicional baseado em planos diretores. Dessa forma destacam-se atributos positivos dos planos estratégicos como: ser orientado à ação e à implantação levando em consideração os recursos necessários; ser flexível; ter foco no processo de planejamento; promover a integração de políticas públicas; entre outros.

A unidade de política de desenvolvimento urbano econômico do Hábitat da Nações Unidas no contexto do processo preparatório para a Nova Agenda Urbana destacou, por meio de seu relatório (United Nations Conference on 
Housing and Sustainable Urban Development, 2017), a importância de as cidades desenvolverem uma visão estratégica de longo prazo de forma que ela se torne referência para atração de investimentos e para a articulação de políticas públicas. Destacou ainda que o plano estratégico associado a essa visão deveria ser flexível.

O objetivo deste trabalho é discutir como o planejamento estratégico de longo prazo pode direcionar o desenvolvimento das cidades. Ênfase será dada ao potencial que o planejamento estratégico de longo prazo tem para ser um instrumento efetivo de planejamento para as cidades brasileiras. Duas iniciativas de planejamento estratégico para cidades brasileiras são apresentadas de forma resumida para ilustrar os conceitos discutidos neste artigo e para exemplificar a aplicação do planejamento estratégico no contexto brasileiro. Pretende-se também abordar características desejáveis dos planos estratégicos e seus conteúdos fundamentais.

\section{O papel do planejamento estratégico no desenvolvimento das cidades}

Cidades consistem num conjunto de realidades extremamente complexas, que constituem o palco de dinâmicas sociais e econômicas que acontecem em certo espaço físico a partir de um estágio de implantação das infraestruturas urbanas, interagindo com o meio ambiente natural. Planejar as cidades e criar mecanismos adequados para que esse planejamento direcione realmente o que acontece na cidade é um desafio monumental. É nesse contexto que se insere o planejamento estratégico de longo prazo entendido como um processo contínuo que busca conduzir a cidade para um futuro desejado, segundo um conjunto de conteúdos, características e requisitos próprios. O planejamento estratégico tem também se revelado um instrumento poderoso para que as cidades, em nível mundial, enfrentem de forma integrada seus desafios de ordem social, econômica e ambiental (Clark, 2013).

O estudo já mencionado na Introdução (Rapoport; Acuto; Grcheva, 2018) enfatiza que o planejamento estratégico é um importante instrumento de liderença nas cidades e ao examinar as diversas iniciativas de planejamento estratégico reconhece que há uma significativa variabilidade nos planos - por exemplo, em relação a sua escala de tempo, a sua área de abrangência, a ser ou não uma lei e ao seu processo de construção.

Na sequência examinam-se os conteúdos que no entendimento do autor seriam os mais relevantes para um plano estratégico de longo prazo.

\section{Conteúdos:}

\section{Visão de futuro}

A construção de uma visão de futuro que sintetize as aspirações da cidade no longo prazo é um elemento fundamental de um plano estratégico. Ela pressupõe o entendimento da relação da cidade com a rede de cidades com que in- 
terage, de seus grandes desafios e oportunidades, das aspirações de seus cidadãos e da construção e avaliação de cenários de futuro. A partir desses elementos e no contexto do processo de participação que engaje seus cidadãos, a visão emerge como a convergência para um futuro compartilhado e desejado.

\section{Conjunto de objetivos}

Estabelecer um conjunto de objetivos que conduzam à visão de futuro é essencial. Os objetivos devem ser suficientemente estratégicos para abarcar as grandes transformações e iniciativas, mas não devem abranger todas as realizações possíveis. Um plano estratégico deve ser seletivo e focar no que realmente transforma a cidade no longo prazo.

Portanto, seus objetivos devem priorizar o que é essencial para se atingir a visão de longo prazo. É natural que políticas públicas setoriais que são importantes para a cidade sejam elaboradas e implantadas sem estarem necessariamente detalhadas no plano estratégico. Por exemplo, é evidente que toda cidade deseja ter um bom sistema educacional e é natural que ela busque uma política educacional que, respeitando a legislação sobre o tema, procure maximizar os resultados positivos. O plano estratégico deve focar na definição dos objetivos que, relacionando-se à temática educacional, possam conduzir à cidade desejada. Um plano estratégico não é a soma de uma infinidade de planos setoriais.

\section{Estratégia de implantação}

O plano estratégico deve ter como conteúdo intrínseco um plano de ação. É necessária uma estratégia de implantação que envolva hierarquização dos projetos e ações, um macro cronograma e as fontes de recursos, mesmo que dependam de parcerias e acordos.

\section{Processo de construção do plano}

A legitimidade do plano estratégico de longo prazo está ancorada em ele, de fato, refletir os anseios da cidade. Não se trata de buscar a unanimidade por parte de todos os seus moradores - o que seria até ingênuo -, mas sim de buscar uma pactuação majoritária do que se deseja no longo prazo e de quais serão os grandes caminhos a percorrer. Isso só pode ser alcançado se o plano resultar de um esforço genuíno de construção coletiva. Reconhece-se, de pronto, que esse talvez seja o maior desafio para a elaboração do plano estratégico, desafio que se mostra proporcional ao porte da cidade. O processo de construção do plano requer uma cuidadosa preparação que especifique as diversas etapas desse processo e as formas de participação, de modo a envolver tanto o cidadão como as lideranças da sociedade civil organizada, desde as fases iniciais da elaboração do plano até a sua forma final.

O plano estratégico em sua forma final nem sempre resulta em uma lei. $\mathrm{O}$ estudo da UCL (Rapoport; Acuto; Grcheva, 2018), já mencionado, mostra que em $66 \%$ das 29 cidades para as quais os planos estratégicos foram estudados, eles não têm a forma de lei. Considerando o arcabouço jurídico brasileiro atual, o 
plano estratégico não seria necessariamente uma lei: o que lhe emprestaria força seria o reconhecimento genuíno da cidade dele representar sua vontade coletiva e, portanto, pertencer à cidade. A relação do plano estratégico com a legislação urbanística brasileira será discutida adiante.

\section{Processo de monitoramento e avaliação}

Num plano estratégico de longo prazo estamos falando de duas, três ou mais décadas. Seria até ingênuo pensar que se poderia estabelecer, em um dado momento, um plano para ser seguido à risca durante todo seu horizonte temporal. Há mudanças dos condicionantes que existiam quando da elaboração do plano que não se poderiam antecipar. As mudanças tecnológicas no setor da comunicação e informação que revolucionaram como as pessoas interagem e se comunicam são um exemplo cristalino disso. Portanto, é imprescindível que haja um sistema de monitoramento da implantação do plano que contenha indicadores e metas de forma a controlar o progresso de sua implantação e mecanismos e estruturas que permitam a sua avaliação e a proposição de ajustes. Dessa forma, é necessário entender o plano estratégico como um processo. Por outro lado, a visão e os grandes objetivos são em geral perenes. Os ajustes estão mais ligados aos meios de alcançá-los.

\section{Potencial para o planejamento estratégico de longo prazo ser um instrumento efetivo de planejamento}

A Constituição brasileira trata expressamente do planejamento, dispondo, de modo geral, que, "como agente normativo e regulador da atividade econômica, o Estado exercerá, na forma da lei, as funções de fiscalização, incentivo e planejamento, sendo este determinante para o setor público e indicativo para o setor privado" (art. 174). Certos instrumentos de planejamento, como o plano plurianual, a lei de diretrizes orçamentárias e o orçamento anual (art. 165), assim como o plano diretor (art. 182), foram objeto de menção constitucional específica. Contudo, não há uma sistematização estrita entre os planos no que se refere a relações de hierarquia e interdependência. Nota-se, de todo modo, que os instrumentos expressamente referidos tratam de matérias específicas, correspondentes ao aspecto financeiro-orçamentário e ao ordenamento territorial. Não há previsão de um plano mais abrangente do ponto de vista temático, nem de algo especificamente voltado aos resultados de longo prazo.

Essas questões mostram nuances mais claras no caso do plano diretor, que detém algum protagonismo em âmbito municipal. Ao estabelecer o plano diretor como instrumento básico da política de desenvolvimento e expansão urbana, os artigos 182 e 183 da Constituição Federal, que foram regulamentados pela Lei n.10.257, de 10 de julho de 2001 - conhecida como Estatuto da Cidade -, dão ênfase à disciplina da atuação dos diversos entes que interagem na cidade no que diz respeito à propriedade e ao uso do solo urbano. Sem embargo, não há um consenso a respeito do que constituiria a matéria do plano diretor. A norma federal à qual caberia delimitar tal temática, o Estatuto da Cidade (Lei 
n.10.257/01), indica matérias a serem tratadas no plano diretor (art. 42), mas com pouco rigor. Na verdade, tal lei se refere a um conteúdo mínimo, que deixa de fora, por exemplo, o próprio ordenamento territorial. Nesse cenário, há pouca segurança para afirmar, por exemplo, se seria admissível atribuir eficácia jurídica a dispositivos de um plano diretor que tratassem de escopos mais amplos, como o desenvolvimento econômico ou até mesmo certas políticas setoriais (Brega, 2017).

Na referência (Santos Jr.; Montandon, 2011), conduzida sob a coordenação do Ministério das Cidades, reportam-se os resultados de pesquisa qualitativa sobre planos diretores que foram elaborados após a entrada em vigor do Estatuto da Cidade. De forma geral, a pesquisa identificou uma ênfase nos temas de zoneamento, gestão do uso do solo, sistema viário, habitação e patrimônio histórico e, em menor grau, saneamento ambiental e mobilidade urbana. De forma ampla, a pesquisa identificou várias deficiências que também são percebidas no exame de planos diretores selecionados ao acaso. Em alguns casos, verificou-se a simples transcrição de trechos do Estatuto da Cidade, sem vinculação com a realidade municipal ou de forma desarticulada. Em outros casos, os instrumentos de política urbana não tiveram sua utilização demarcada no território municipal. Várias políticas setoriais, como habitação, saneamento ambiental e mobilidade, são muitas vezes tratadas de forma frágil, referindo-se a planos a serem desenvolvidos posteriormente.

A pesquisa reforça a percepção de que, elaborados tão somente para cumprir o dever constitucional que é imposto às cidades com mais de 20 mil habitantes, muitos planos diretores não conseguem direcionar o desenvolvimento do município naquilo que deveria ser seu conteúdo precípuo: o uso do solo e as infraestruturas urbanas. Por outro lado, um plano diretor deve ter subjacente uma visão de futuro e uma cidade desejada, o que raramente se depreende da análise de um plano diretor específico.

As cidades brasileiras abrigam cerca de $84 \%$ de sua população e são onde ocorre grande parte das dinâmicas sociais, econômicas, culturais e de formação nos diversos níveis no Brasil. As cidades, por propiciarem os contatos face a face entre seus habitantes, constituem o ambiente apropriado para moldar os avanços e as inovações nas técnicas de produção, nas áreas tecnológicas, culturais e artísticas. É também na cidade que grande parte das necessidades da população brasileira é atendida. Citam-se educação, saúde, proteção social, segurança, lazer, locomoção entre outras. Essa complexidade é reconhecida quando do ponto de vista regulatório listam-se os instrumentos de política urbana no artigo $4^{\circ} \mathrm{da}$ Lei n.10.257 que vão de planos nacionais, regionais e estaduais de ordenação do território e de desenvolvimento econômico e social, passando por planejamento das regiões metropolitanas, aglomerações urbanas e microrregiões, incluindo o plano diretor, a disciplina do parcelamento, uso e ocupação do solo e planos de desenvolvimento econômico e social. 
É nesse contexto que se insere o planejamento estratégico de longo prazo. Ele pode ser entendido como um esforço voluntário de pactuação e concertação dos diversos entes que interagem na cidade, poder público, setor privado e sociedade civil organizada entre outros, por um futuro da cidade desejado. O conjunto de conteúdos, características e requisitos do planejamento estratégico já foram discutidos antes e não serão repetidos aqui. No entanto, é fundamental destacar que não há conflito entre o planejamento estratégico de longo prazo e o arcabouço regulatório mencionado acima. Consensuar uma visão de longo prazo, estabelecer objetivos e priorizar um conjunto de ações são iniciativas que devem ter sinergia com a legislação existente que se relaciona com a cidade, podendo-se constituir numa referência importante para seu aperfeiçoamento, para sua integração e para o alinhamento dos diversos instrumentos de política urbana. Por outro lado, reconhece-se que a existência do conjunto de instrumentos de política urbana preconizados no artigo $4^{\circ}$ da Lei n.10.257 que potencialmente poderia vir a ser desenvolvido não garante, por si só, que a atuação dos agentes privados, do poder público e a sociedade civil organizada produzam no longo prazo resultados que reflitam interesses compartilhados e equilibrados da cidade. Dessa forma, percebe-se tanto o valor intrínseco do planejamento estratégico de longo prazo, bem como sua relevância, e as cidades brasileiras se beneficiaram muito de ter adicionalmente aos instrumentos de política urbana, o planejamento estratégico de longo prazo.

Nesse contexto é importante enfatizar a importância do plano diretor e descartar qualquer potencial conflito conceitual entre o plano diretor e o plano estratégico de longo prazo. De fato, eles têm escopos com abrangências diferentes: enquanto o plano diretor tem foco no uso do solo e nas infraestruturas urbanas, o plano estratégico de longo prazo aborda de forma integrada desenvolvimento econômico, social e urbano, e melhoria ambiental. Também aborda uso do solo e infraestruturas, mas nesse contexto mais amplo. Uma diferença fundamental é que o plano diretor é regulatório, ou seja, regra a ação dos vários agentes que atuam na cidade, principalmente do setor privado. Por outro lado, o plano estratégico de longo prazo articula os agentes na busca dos objetivos pactuados. Enquanto o plano diretor se restringe ao município, cabendo-lhe regrar o uso do solo para esse ente federativo, o plano estratégico de longo prazo busca articular as várias esferas de governo, já que seu conteúdo, em geral, tem projetos e objetivos que demandam a atuação concertada dessas várias esferas. Planos estratégicos de longo prazo têm uma escala temporal de duas, três e até mais décadas, ao passo que, para o plano diretor, a escala mais usual é de uma década.

Apesar das diferenças destacadas acima, há uma evidente sinergia entre os dois planos. Para que o plano estratégico de longo prazo possa ter sucesso é fundamental que a regulação estabelecida no plano diretor para o uso do solo e para as infraestruturas urbanas seja compatível com o que preconiza o plano 
estratégico. Por outro lado, na medida em que, de fato, haja essa compatibilidade, o plano diretor será um instrumento poderoso para a realização do plano estratégico. Conceitualmente, no cenário ideal, o desenvolvimento do plano estratégico deveria ocorrer antes daquele do plano diretor e se tornar importante referência para sua elaboração. Da mesma forma, a lei de parcelamento, uso e ocupação do solo deveria ocorrer após o plano diretor, traduzindo seus conceitos para uma escala espacial menor. Essa relação de interdependência está mostrada na Figura 1.

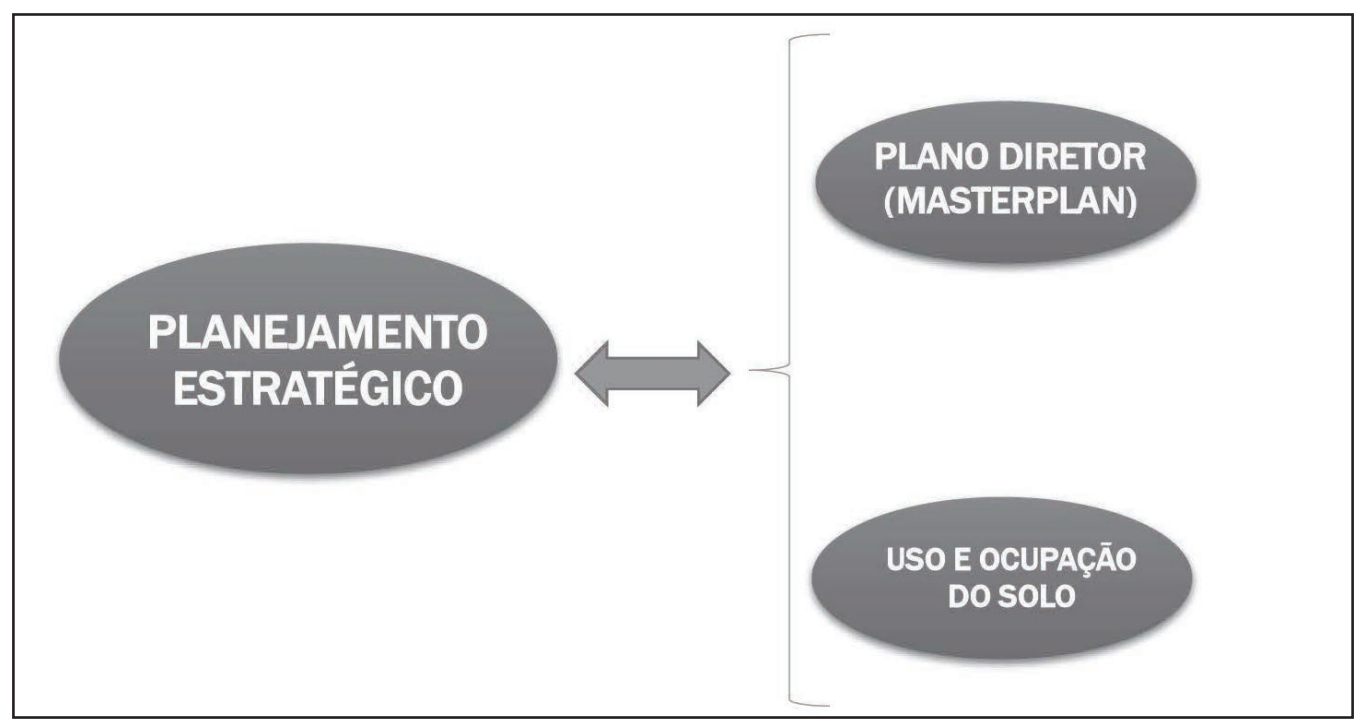

Figura l - Relações de interdependência para instrumentos de planejamento.

Considerando a realidade brasileira em que o plano diretor é obrigatório para cidades com mais de 20 mil habitantes e que o plano estratégico atualmente não tem status de lei, sendo uma iniciativa volitiva de uma cidade, é relevante discutir como a harmonia preconizada na Figura 1 deveria ocorrer. Seria uma situação bastante normal aquela em que uma cidade com um plano diretor aprovado tenha a iniciativa de desenvolver um plano estratégico. Ao final do desenvolvimento do plano estratégico há a real possibilidade de haver incompatibilidades entre o plano estratégico e o plano diretor previamente aprovado. O caminho natural seria que o plano diretor fosse revisado para se tornar compatível com o plano estratégico. No entanto, isso pode não ocorrer pois a revisão do plano diretor envolve todo um rito, inclusive a aprovação legislativa. Nessa situação indesejada seria forçoso reconhecer que a etapa "processo de construção do plano estratégico" descrita antes tivesse sido deficiente, pois não teria resultado de um esforço genuíno de construção coletiva que permitisse ao plano estratégico ser reconhecido como o instrumento representativo da vontade coletiva rumo ao futuro desejado. Se assim fosse, ou seja, um instrumento representante da vontade coletiva, seria natural que as aprovações necessárias para compatibilizar a plano diretor e o plano estratégico ocorressem. 
A discussão acima sinaliza para o grande potencial positivo que planos estratégicos de longo prazo teriam não somente para direcionar o desenvolvimento das cidades brasileiras, mas também para promover esse desenvolvimento. Ademais, tais planos têm uma relação de sinergia com os demais instrumentos de política urbana previstos no Estatuto da Cidade, em especial, com o plano diretor e a disciplina do parcelamento, uso e ocupação do solo. No caso em que a elaboração do plano estratégico precede a do plano diretor ou de sua revisão, o plano estratégico deveria ser referência importante para a elaboração do plano diretor.

\section{Iniciativas de planejamento estratégico no contexto brasileiro}

Mencionam-se duas iniciativas de planejamento estratégico no contexto brasileiro: o SP2040 e o SJBV2050, planos estratégicos de longo prazo para as cidade de São Paulo e de São João da Boa Vista, respectivamente. Pelas suas escalas totalmente distintas - São Paulo com mais de 12 milhões de habitantes e São João da Boa Vista com cerca de 90 mil habitantes - são exemplos de como o planejamento estratégico de longo prazo pode ter um papel relevante para um amplo espectro de cidades brasileiras. Não é objetivo discutir neste trabalho os conteúdos desses planos, que estão detalhados em suas respectivas publicações (SP2040, 2012) e (SJBV2050, 2016), mas caracterizar de forma resumida essas iniciativas e destacar aspectos que indiquem oportunidades e desafios para o planejamento estratégico de longo prazo das cidades brasileiras.

Os conteúdos básicos de planos estratégicos descritos antes estão presentes em ambos os planos. Um diagnóstico de profundidade no qual se consideram os condicionantes ambientais, sociais, econômicos e urbanísticos (uso do solo e infraestruturas urbanos) são elementos fundamentais dos dois planos. Nas Figuras 2 e 3 estão mostradas, respectivamente, as estruturas dos planos SP2040 e SJBV2050, que foram extraídas das publicações editadas para a divulgação dos planos (SP2040, 2012; SJBV2050, 2016).

No SP2040, os desequilíbrios estruturais que emergiram do diagnóstico estão explicitados e constituem os grandes desafios a serem superados no longo prazo. No SJBV2050, apesar de não estarem explicitados na estrutura do plano, os desequilíbrios também foram identificados e sua superação orientou muitas das propostas ali apresentadas.

Elemento central de planos estratégicos, a visão está destacada na estrutura dos dois planos e não resultou apenas de uma análise técnica, mas refletiu as aspirações das cidades no longo prazo que foram captadas por meio do processo de participação.

Como destacado antes, o processo de construção do plano é um dos grandes desafios. No caso da cidade de São Paulo, esse desafio é ainda maior, dada sua população, suas dimensões territoriais e sua complexa rede de atores da sociedade civil organizada. Esse processo exigiu um desenho cuidadoso. Por um lado, foi ouvido um grande número de especialistas de diversas áreas sobre quais 


\section{VISÃO: A CIDADE QUE QUEREMOS}
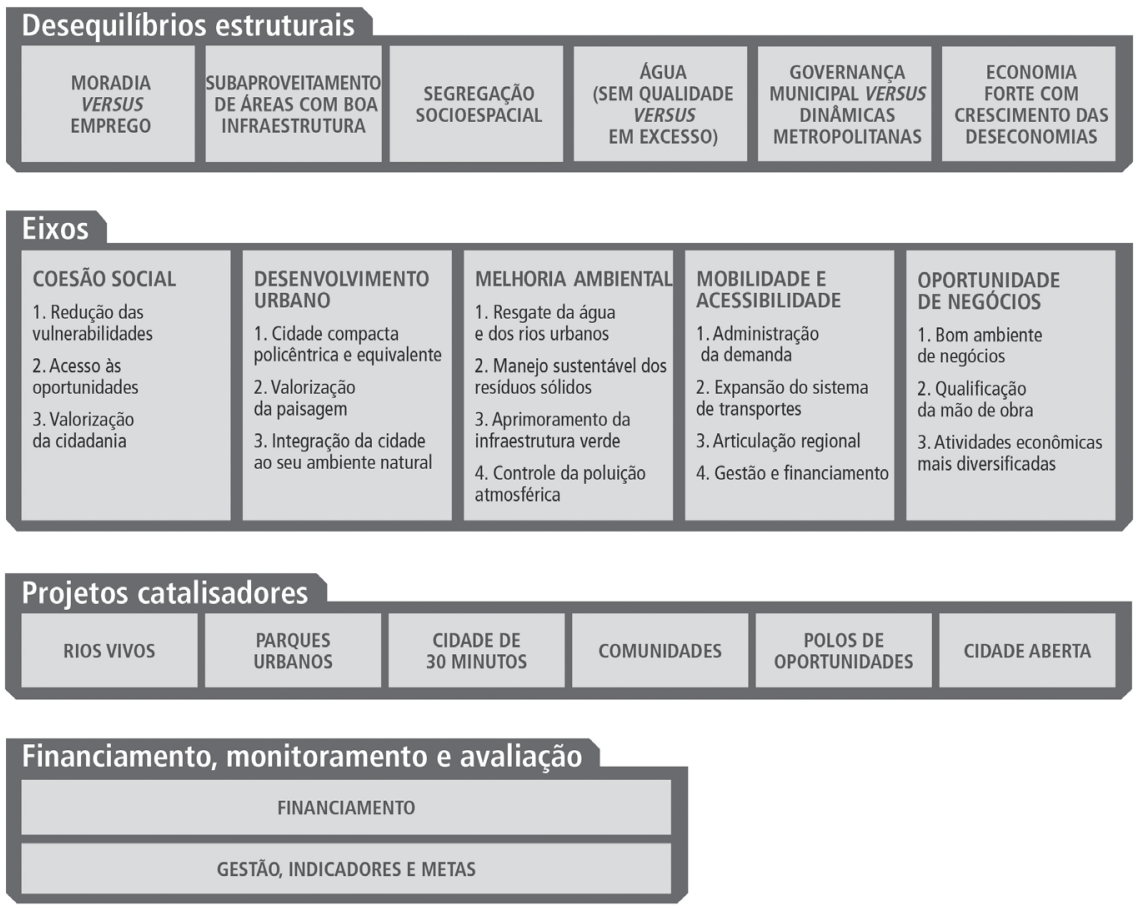

Fonte: Secretaria Municipal de Desenvolvimento Urbano. SP 2040: A Cidade que queremos. São Paulo, 2012, p.21.

Figura 2 - Estrutura do SP2004.

seriam os grandes desafios da cidade e os caminhos para superá-los. Foram elaborados questionários detalhados que demandaram um grande esforço técnico que foi lastreado pela elaboração do diagnóstico. Foi usada a técnica WebDelphi (Wright; Giovinazzo, 2000) para sua consecução. Ouvir a população da cidade, o que é essencial, exigiu várias iniciativas concorrentes. Foram realizadas: oficinas públicas em diversas regiões da cidade (aqui se utilizaram as subprefeituras, que constituíam a designação para a divisão administrativa da cidade na época); fórum de debates virtual; aplicação de questionários tanto pela internet quanto por meio de entrevistadores atuando em pontos de grande fluxo de pessoas, como estações de trem e de metro, terminais de ônibus, aeroportos e parques, entre outros; interação com a sociedade civil organizada, que se deu por meio do Conselho Consultivo do Plano, congregando 23 entidades representativas dos trabalhadores, do comércio, dos serviços, da indústria, associação de moradores e universidades. Nesse processo de participação envolveram-se aproximadamente 25 mil paulistanos, o que, considerada a abrangência territorial das atividades e a diversidade de perfis dos participantes, forneceu uma amostra significativa da população da cidade. 


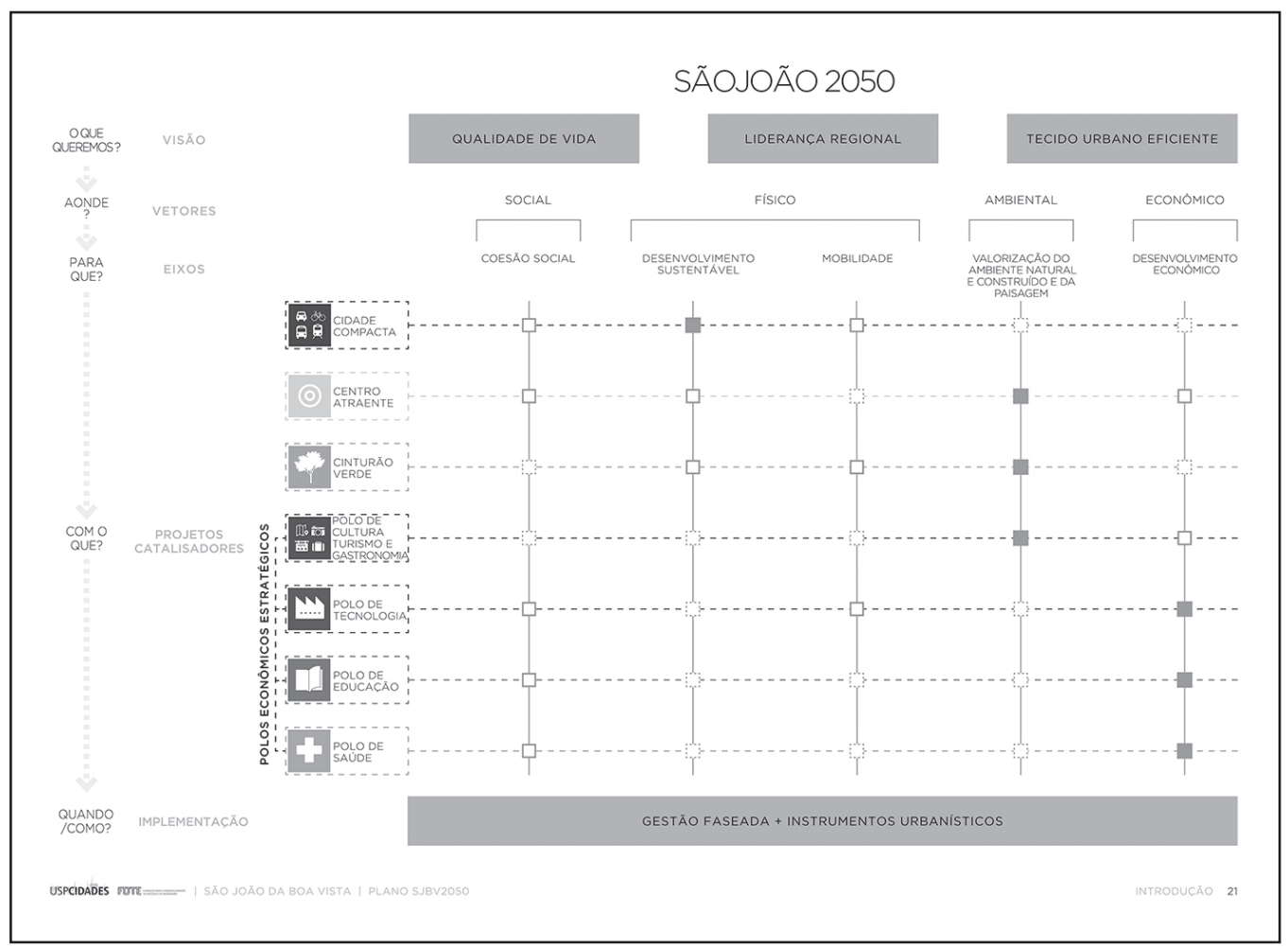

Fonte: Prefeitura Municipal de São João da Boa Vista, Plano São João 2050, São João da Boa Vista, 2016. Disponível em: <http://www.saojoao2050.com.br/plano-estrategico>, p.21.

Figura 3 - Estrutura do Plano São João da Boa Vista 2050.

O processo de participação em São João da Boa Vista utilizou a rede de escolas públicas para propiciar a oportunidade de participação em cada bairro. A determinação em favor da existência de um processo intensamente participativo levou à utilização de 119 horas de carros de som e à distribuição de 40 mil folhetos em residências, além de divulgação em jornais, televisão, rede sociais, entre outras. Houve ainda cerca de 70 encontros técnicos para a discussão e construção de conteúdos do plano mobilizando os atores e entidades da sociedade civil organizada. As discussões foram ainda potencializadas pelo fórum "on line" e por um aplicativo para "smartphones" específico para a participação na construção do plano. Merece destaque pesquisa com jovens moradores da cidade de 14 a 29 anos, com uma concentração na faixa etária de entre 15 e 19 anos (92\% do total), que procurou captar os comportamentos socioculturais e as perspectivas de futuro desses jovens tendo sido respondidos 1960 questionários em 119 bairros diferentes.

Ambos os planos organizam os seus objetivos, propostas e ações por meio de eixos estruturadores e projetos catalisadores. Os eixos estruturadores são temáticos, abordando desenvolvimento social, econômico, urbano e melhoria ambiental. Os projetos catalisadores constituem-se em programas que são niti- 
damente transversais em relação aos eixos estruturadores. O grande objetivo de cada projeto catalisador é de fácil percepção pela população e sua implementação tem o condão de conduzir a cidade para a concretização de sua visão.

Pela análise dos conteúdos dos eixos e dos projetos catalisadores percebe-se que eles refletem os desafios e oportunidades específicas de cada cidade e sua visão de futuro. Por exemplo, o projeto catalisador "Cidade Aberta" do plano SP2040 está muito ligado ao fato de São Paulo ser uma cidade global, buscando o fortalecimento de sua posição nas redes internacionais de negócios, finanças, turismo e informação.

O projeto catalisador "Cidade de 30 minutos", também parte do SP2040, endereça de forma muito clara um dos principais desafios da cidade: o longo tempo que seus moradores despendem para chegar ao trabalho e retornar aos seus domicílios, o que é uma consequência da localização desequilibrada de oportunidades de trabalho e moradias. Na última pesquisa origem-destino, atualizada em 2012, a média de tempo despendida nas viagens de trabalho era de 49 minutos. No entanto, muitas viagens duram muito mais do que os 49 minutos. Por exemplo, nessa mesma data, a média de tempo das viagens que envolviam o transporte público era de 74 minutos. Esse objetivo claro, de reduzir o tempo médio das viagens de trabalho para 30 minutos, é facilmente compreendido pelos moradores da cidade e o atendimento dessa meta levaria a uma grande melhoria da qualidade de vida da população e da eficiência econômica da cidade. Por outro lado, o programa de iniciativas necessárias para se atingir esse objetivo é extremamente abrangente, requerendo tanto a expansão da rede de transportes de média e alta capacidade quanto a implantação de uma estratégia de redesenvolvimento urbano onde se busca a intensificação do uso do solo nas áreas que têm infraestrutura de transporte, privilegiando o uso misto e a mistura de renda. A transversalidade das ações desse projeto catalisador é evidente, bem como a simplicidade e a relevância de seu objetivo.

No caso de São João da Boa Vista, o projeto catalisador "Polos Econômicos Estratégicos" está lastreado na oportunidade de potencializar a liderança que São João já exerce na sua região em várias atividades econômicas, de forma a propiciar um importante vetor de desenvolvimento econômico. Estabelece um programa de ações para dinamizar as atividades ligadas a educação, saúde, tecnologia, cultura, turismo e gastronomia, observado que as atividades ligadas a educação, por terem um efeito multiplicador, serão essenciais para o sucesso do programa nas demais áreas. Talvez o maior desafio de São João seja evitar o espraiamento urbano que começou a se configurar a partir da proliferação de loteamentos residenciais nas áreas periféricas de sua mancha urbana. A contenção desta expansão e a criação de condições para que o desenvolvimento urbano ocorra de forma orgânica e majoritariamente em sua área já urbanizada são essenciais para cidade, estando as estratégias para tal contidas nas propostas do plano e, em particular, no projeto catalisador "Cidade Compacta". 
Os eixos estruturadores em ambos os planos contêm um conjunto de objetivos e cada objetivo um conjunto de propostas. Dessa forma, ganha-se concretude para implementação do plano dentro de um contexto hierárquico. Os projetos catalisadores delineiam um conjunto de ações e há muitas propostas dos eixos que colaboram para os programas dos projetos catalisadores.

Ambos os planos abordaram as estratégias de implantação. No caso de São Paulo, o nível de detalhamento que foi possível obter dos projetos catalisadores foi bem maior pois, em vários deles, foram articuladas iniciativas existentes, na maioria das vezes desenhadas com uma visão setorial, que vieram, por meio do projeto catalisador, compor um programa integrado. Por exemplo, no "Cidade de 30 minutos" a expansão do sistema de média e alta capacidade já tinha um desenho de linhas, o qual se integrou a uma estratégia de redesenvolvimento que foi articulada como uma contribuição do plano. Foi então possível para o SP2040 fazer uma estimativa dos recursos necessários para a implantação dos projetos catalisadores que está detalhada na Tabela 1 reproduzida do plano. Nota-se que há uma partição dos recursos necessários pelas esferas de governo que teriam a governança de partes das iniciativas requeridas. Com base nesses valores foi possível avaliar a viabilidade financeira no que dependia do município, considerando condicionantes de arrecadação e captação de recursos extra orçamentários em um contexto de cenários de futuro.

Tabela 1 - Custos estimados SP 2040

Estimativa de recursos externos e Municipais por Projeto catalisador - em R\$ Milhão

\begin{tabular}{l|c|c|c|c|c}
\hline Projeto catalisador & $\begin{array}{c}\text { Custo } \\
\text { total } \\
\text { da União ou do Governo } \\
\text { do Estado }\end{array}$ & $\begin{array}{c}\text { Projetos de governança } \\
\text { governança } \\
\text { Municipal }\end{array}$ & $\begin{array}{c}\text { Recursos } \\
\text { externos }\end{array}$ & $\begin{array}{c}\text { Previsão de } \\
\text { recursos do } \\
\text { Município }\end{array}$ \\
\hline Cidade aberta & 32.600 & 29.900 & 2.700 & 2.700 & 0 \\
\hline $\begin{array}{l}\text { Cidade de 30 } \\
\text { minutos }\end{array}$ & 178.857 & 149.808 & 29.049 & 736 & 28.313 \\
\hline $\begin{array}{l}\text { Comunidades } \\
\text { darques }\end{array}$ & 192.625 & 7.702 & 54.923 & 38.763 & 16.610 \\
\hline urbanos & 16.443 & 0 & 1.995 & 0 & 1.995 \\
\hline oportos de & 314.493 & 14.833 & 111.997 & 43.809 & 67.789 \\
\hline Rios vivos & 202.896 & 1.610 & 1.610 & 0 \\
\hline
\end{tabular}

Fonte: Secretaria Municipal de Desenvolvimento Urbano. SP 2040: A Cidade que queremos. São Paulo, 2012, p.321. 
No caso de São João da Boa Vista, vários projetos catalisadores foram contribuição do plano, não tendo um nível de detalhamento que permitiria fazer estimativas confiáveis. Dessa forma, indicaram-se para cada projeto catalisador as fontes de recursos que poderiam ser consideradas quando do detalhamento desses projetos.

Sobre o processo de monitoramento e avaliação no SP2040, estabeleceu-se um conjunto sucinto de indicadores de resultados compatíveis com a natureza estratégica do plano. Os indicadores procuram quantificar as grandes transformações almejadas pelos projetos catalisadores, de modo a serem de fácil entendimento pela população. De modo associado a cada indicador, foram definidas metas com dois horizontes temporais para seu atingimento: 2025 e 2040. $\mathrm{O}$ processo de avaliação estaria ancorado no Conselho Consultivo do Plano definido anteriormente, que representaria a sociedade civil organizada, criando o instrumento para que ela fosse a efetiva guardiã do plano. Esse conselho seria responsável pelo acompanhamento do cumprimento da metas, do desenvolvimento dos projetos, da priorização dos recursos e pela mediação da constante interação com a sociedade com vistas a sua atualização, tornado o plano um instrumento vivo e o planejamento estratégico um processo contínuo. Também faria a ligação entre a administração pública e a sociedade civil organizada, de forma que a administração pública se engajasse em dar o suporte técnico para que o Conselho pudesse funcionar.

Para São João da Boa Vista o plano propõe a criação de um conselho gestor que teria papel análogo ao Conselho Consultivo de SP2040, ao qual caberia o estabelecimento dos indicadores e metas que fossem compatíveis com o detalhamento dos projetos catalisadores.

\section{Considerações finais}

Procurou-se evidenciar o grande potencial que o planejamento estratégico de longo prazo tem para fomentar o desenvolvimento social, econômico e urbano das cidades alinhados a uma visão de futuro da cidade desejada.

No caso brasileiro esse potencial é muito significativo não só pelo alto nível de urbanização do país, mas também pelos monumentais desequilíbrios que as áreas urbanas têm e cuja superação exige uma estratégia sustentada de longo prazo.

Examinaram-se as características desejáveis de planos estratégicos de longo prazo. Ao discutirem-se essas características se evidenciam os potenciais benefícios que podem ser obtidos com o desenvolvimento desses planos de forma a propiciar um processo de planejamento de longo prazo que empodere a cidade, no sentido mais amplo - dos seus diversos atores -, a assumir o controle de seu destino no longo prazo.

Importante destacar, como mostrou a discussão precedente, que não há conflito do plano estratégico de longo prazo e os demais instrumentos de planejamento urbano previstos na legislação urbanística brasileira, mas sim sinergia. 
Referências

ALBRECHTS, L. Strategic (spatial) planning reexamined. Environment and Planning B: Planning and Design v.31, n.5, p.743-58, 2004.

BREGA, J. F. F. Plano Diretor e Estatuto da Cidade: estruturas jurídicas e efetividade do planejamento. In: ALMEIDA, M. e LEVY, W. Temas fundamentais do direito urbanístico e imobiliário. São Paulo: Quartier Latin do Brasil, 2017.

CITIES ALLIANCE. Guide to City Development Strategies: Improving Urban Performance. Washington, DC: Cities Alliance, 2006. Disponível em: <http://www.citiesalliance.org/node/737>.

CLARK, G. The Future of Cities: The Role of Strategic Planning. Future Studies Research Journal, São Paulo, v.5, n.1, p.3-32, jan./jun. 2013.

PREFEITURA MUNICIPAL DE SÃO JOÃO DA BOA VISTA. Plano São João 2050, São João da Boa Vista, 2016. Disponível em: <http://www.saojoao2050.com.br/plano-estrategico>.

RAPOPORT, E.; ACUTO, M.; GRCHEVA L. Leading Cities: A Global Review of City Leadership. London: UCL Press, 2018.

SANTOS JUNIOR, O. A.; MONTANDON, D. T. Os Planos Diretores Municipais pós-estatuto da cidade: balanço crítico e perspectivas. Rio de Janeiro: Letra Capital, 2011.

SECRETARIA MUNICIPAL DE DESENVOLVIMENTO URBANO. SP 2040: A Cidade que Queremos. São Paulo, 2012.

UNITED NATIONS CONFERENCE ON HOUSING AND SUSTAINABLE URBAN DEVELOPMENT. Habitat III Policy Papers: Policy Paper 7 Urban Economic Development Strategies New York: United Nations, 2017. Disponível em: <www.habitat3. org >.

UN HABITAT Planning Sustainable Cities: Global Report on Human Settlements Nairobi, Kenya, 2009. Disponível em: <http://unhabitat.org/books/global-report-on-human-settlements-2009-planning-sustainable-cities/>.

WRIGHT, J. C.; GIOVINAZZO, R. Uma ferramenta de apoio ao planejamento prospectivo. Cadernos de Pesquisas em Administração, São Paulo, v.1, n.12, $2^{\circ}$ semestre 2000 .

RESUMO - Discute-se como o planejamento estratégico de longo prazo pode direcionar o desenvolvimento das cidades. Ênfase é dada ao potencial que o planejamento estratégico de longo prazo tem para ser um instrumento efetivo de planejamento para as cidades brasileiras. Duas iniciativas de planejamento estratégico para cidades brasileiras são apresentadas de forma resumida para ilustrar os conceitos discutidos neste artigo e para exemplificar a aplicação do planejamento estratégico no contexto brasileiro. Abordam-se características desejáveis dos planos estratégicos e seus conteúdos fundamentais.

PALAVRAS-CHAVE: Cidades, Planejamento estratégico, Planejamento urbano, Instrumentos urbanísticos. 
ABSTRACT - This article discusses how long-term strategic planning may direct the development of cities, emphasizing the potential that long-term strategic planning has to be an effective planning instrument for Brazilian cities. Two initiatives of strategic planning for Brazilian cities are summarized to illustrate the concepts under discussion and to exemplify the use of strategic planning in the Brazilian context. The desirable characteristics and the fundamental concepts of strategic planning are also discussed. KEYWORDS: Cities, Strategic planning, Urban planning, Urban instruments.

Miguel Luiz Bucalem é professor titular na Escola Politécnica da USP, coordenador científico do Núcleo de Apoio à Pesquisa USP Cidades. @ - mlbucale@usp.br / https://orcid.org/0000-0002-2646-6728

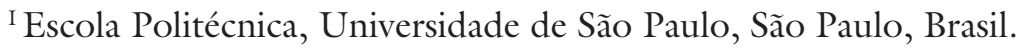

Recebido em 14.9.2018 e aceito em 29.11.2018. 
